\title{
MURCIÉLAGOS HEMATÓFAGOS COMO RESERVORIOS DE LA RABIA
}

\author{
Karin Corrêa Scheffer ${ }^{1, a}$, Keila lamamoto ${ }^{1, a}$, Karen Miyuki Asano1,a, Enio Mori, ${ }^{1, a}$, \\ Andrea Isabel Estevez Garcia ${ }^{2, a}$, Samira M. Achkar ${ }^{1, b}$, Willian de Oliveira Fahl11,b
}

\begin{abstract}
RESUMEN
La rabia continua siendo un desafío para las autoridades de salud pública y una limitante para la industria ganadera en América Latina. Caninos silvestres y domésticos, así como murciélagos hematófagos son las principales especies transmisoras y reservorios de la enfermedad. Actualmente, se observa variaciones en el perfil epidemiológico de la rabia, donde la especie de murciélago hematófago Desmodus rotundus se constituye en la principal especie transmisora. A lo largo del tiempo se ha acumulado conocimiento sobre la ecología, biología y comportamiento de esta especie y sobre la historia natural de la rabia, lo cual debe conducir a una continua evolución de los métodos de control poblacional de $D$. rotundus, prevención y técnicas de diagnóstico. Aún se desconoce la relación ecológica de esta especie con otras hematófagas y no hematófagas, y queda mucho por mejorar en los sistemas de notificación y vigilancia epidemiológica, así como crear una mayor conciencia entre los ganaderos ante el tema. La comprensión del impacto que las modificaciones ambientales inducidas por el hombre ejercen sobre la dinámica de infección del virus de la rabia en los murciélagos debe ser motivo de investigaciones posteriores. Esto requerirá la combinación de estudios de campo con modelos matemáticos y nuevas herramientas diagnósticas. La presente revisión pretende presentar los aspectos más relevantes sobre el rol de los murciélagos hematófagos como reservorios y transmisores del virus de la rabia.
\end{abstract}

Palabras clave: Murciélagos; Reservorios; Rabia (fuente: DeCS BIREME).

\section{HEMATOPHAGOUS BATS AS RESERVOIRS OF RABIES}

\begin{abstract}
Rabies continues to be a challenge for public health authorities and a constraint to the livestock industry in Latin America. Wild and domestic canines and vampire bats are the main transmitter species and reservoirs of the disease. Currently, variations observed in the epidemiological profile of rabies, where the species of hematophagous bat Desmodus rotundus constitutes the main transmitting species. Over the years, knowledge has accumulated about the ecology, biology and behavior of this species and the natural history of rabies, which should lead to continuous development of methods of population control of $d$. Rotundus as well as prevention and diagnostic tools for rabies. Ecological relationships of this species with other hematophagous and non-hematophagous bats is unknown, and there is much room for improvement in reporting systems and surveillance, as well as creating greater awareness among the farming community. Understanding the impact of human-induced environmental changes on the rabies virus in bats should be cause for further investigation. This will require a combination of field studies with mathematical models and new diagnostic tools. This review aims to present the most relevant issues on the role of hematophagous bats as reservoirs and transmitters of the rabies virus.
\end{abstract}

Key word: Bats; Reservoirs; Rabies (source: MeSH NLM).

Instituto Pasteur. São Paulo, Brasil.

Médica veterinaria. Piracicaba, Brasil.

Médico veterinario; ${ }^{\mathrm{b}}$ biólogo.

Recibido: 08-04-14 Aprobado: 11-06-14

Citar como: Corrêa Scheffer K, Iamamoto K, Miyuki Asano K, Mori E, Estevez Garcia AI, Achkar SM, et al. Murciélagos hematófagos como reservorios de la rabia. Rev Peru Med Exp Salud Publica. 2014;31(2):302-9. 


\section{INTRODUCCIÓN}

La rabia es una zoonosis viral de gran importancia. En la epidemiologia de esta enfermedad los murciélagos hematófagos ocupan un lugar destacado como reservorios y transmisores. Se estima que cada 15 min una persona muere a causa de esta enfermedad y otras 300 son expuestas ${ }^{(1)}$. El agente causal es un virus RNA, de sentido negativo, que pertenece a la familia Rhabdoviridae, genero Lyssavirus, orden Mononegavirales (2). Presenta un envoltorio externo formado por lípidos y glicoproteína (proteína G). Debajo de la envoltura viral está la proteína matriz y la ribonucleoproteína interna (proteína N). Esta proteína está compuesta por el RNA genómico, asociado a las proteínas RNA polimerasa dependiente de RNA y fosfoproteína ${ }^{(2)}$. El género Lyssavirus está formado por varias especies, entre los criterios usados para efectuar dicha subdivisión están: la distancia genética, el perfil antigénico determinado mediante anticuerpos monoclonales dirigidos contra proteínas estructurales del virus, la distribución geográfica y el espectro de hospederos ${ }^{(2)}$.

El virus de la rabia (RABV) es el prototipo del género Lyssavirus, sin embargo, todos los miembros de este grupo causan encefalitis fatales en humanos y una amplia variedad de mamíferos, siendo imposible hacer una diferenciación clínica entre ellas ${ }^{(2)}$. El porcentaje de letalidad es cercano al $100 \%$, aunque han sido registrados casos de cura en humanos mediante coma inducido y terapia de soporte, y cura espontánea en casos de infección experimental en modelos animales, que dejaron importantes secuelas motrices ${ }^{(3,4)}$. En la naturaleza, el virus es transmitido por la saliva de animales infectados a través de mordeduras, es posible la transmisión vía aerosoles en condiciones de laboratorio y a través de membranas mucosas ${ }^{(5)}$. Los caninos domésticos y los murciélagos son los principales reservorios y transmisores del RABV en América Latina. Otros carnívoros como zorros, lobos, coyotes, chacales y mapaches están implicados en el ciclo epidemiológico de la enfermedad en América del Norte y Eurasia, así como especies de mangostas en África ${ }^{(6)}$. La enfermedad afecta de manera significativa especies de importancia pecuaria; ha sido descrita en Brasil la presentación de un ciclo epidemiológico del RABV en primates no humanos de la especie Callithrix jacchus ${ }^{(6,7)}$.

\section{EL ROL DE LOS MURCIÉLAGOS COMO VECTORES Y RESERVORIOS DE RABIA EN LATINOAMÉRICA}

Es importante mencionar que los murciélagos no son solamente importantes reservorios para el RABV sino también de una amplia gama de patógenos que pue- den ser causa de enfermedad en personas y animales domésticos. Las actividades humanas han modificado el medioambiente de tal manera que hay aumento de las posibilidades de contacto con dichas especies y, en consecuencia, la diseminación de dichas enfermedades ${ }^{(8)}$. A comienzos del siglo pasado se consideró, por primera vez, la posibilidad de que los murciélagos puedan desempeñar un papel importante en la propagación de la rabia. Dicha hipótesis surgió de la observación de una epizootia de rabia de grandes en Santa Catarina, Sur de Brasil, en la cual murieron cerca de 4000 bovinos y 1000 equinos, lo cual causó elevadas pérdidas económicas a la población local ${ }^{(9)}$.

El director del Instituto Pasteur de São Paulo, Antonio Carini, constató en 1911 la existencia de un gran número de murciélagos hematófagos e indicios de mordeduras en el ganado ocasionadas por estos durante el día. Se formuló la hipótesis de que la enfermedad que afectaba la región sería la rabia transmitida por un murciélago hematófago. Por medio de informaciones de productores locales se tuvo conocimiento de muertes en el ganado en ambas márgenes del río Itajaí, lo que hacía pensar que los perros no estarían involucrados, pues eran lugares de acceso prácticamente imposible para animales terrestres ${ }^{(9)}$. En 1918, los veterinarios alemanes Haupt y Rehaag (1925), investigaron en la misma región e identificaron la presencia de corpúsculos de Negri en el sistema nervioso central (SNC) de un murciélago, al que hallaron alimentándose sobre un bovino durante el día. Estos investigadores realizaron la primera descripción de rabia en murciélagos no hematófagos de la especie Phyllostoma superciliatum, actualmente clasificado como Artibeus lituratus ${ }^{(10)}$. El hallazgo fue refutado, pues existían dudas sobre la diferenciación entre el $P$. superciliatum (A. lituratus), de hábitos frugívoros, y Desmodus rotundus de alimentación hematófaga ${ }^{(11)}$.

Una década después, de la epidemia de rabia en Santa Catarina, entre 1925 y 1936, la rabia asoló la Isla caribeña de Trinidad, comprometiendo incluso seres humanos. Los médicos Hurst y Pawan (1931) confirmaron que se trataba de RABV transmitido por $D$. rotundus. Se constató que la transmisión ocurría por la mordedura de murciélagos enfermos, lo cuales generalmente después de atacar su presa, morían, siendo posible confirmar en laboratorio la presencia del virus en estos especímenes ${ }^{(12)}$. Después de estos hallazgos, la comunidad científica internacional aceptó que $D$. rotundus podía transmitir el virus de la rabia al hombre y a otras especies. Fue así posible aislar el agente causal a partir de $D$. rotundus y de especies de quirópteros frugívoros como Artibeus planirostris trinitalis, Diclidurus albus y Hemiderma sp., seguidos de ensayos de infección experimental en $D$. rotundus y $A$. lituratus ${ }^{(13)}$. Posteriormente, el RABV fue aislado de 
otros murciélagos hematófagos de la especies Diphylla ecaudata ${ }^{(21)}$ y Diaemus youngi ${ }^{(14,15)}$.

De las tres especies de murciélagos hematófagos, la especie $D$. rotundus es la más común y abundante (16). Los murciélagos hematófagos son observados solamente en América Latina, en la región comprendida entre México y Argentina (16). Esta especie no tolera climas fríos, y no se encuentra en lugares donde la temperatura promedio ambiental sea inferior a $10^{\circ} \mathrm{C}$ en el mes más frio del año, de otro lado, son sensibles a temperaturas muy elevadas, de forma que la exposición entre 37 y $38^{\circ} \mathrm{C}$ puede ser letal (16).

Existen varios relatos de mordeduras de murciélagos a seres humanos. Algunos ocurrieron en las poblaciones indígenas como los yanomami, en Venezuela, en 1979, como consecuencia de la deforestación generada por la actividad minera de explotación aurífera (17). En 1975 , varias personas fueron mordidas por $D$. rotundus en Belice, Centroamérica, después del sacrificio de animales de importancia pecuaria en esta área (18). En una villa en el área rural de Brasil, los ataques se distribuyeron en función de cambios ambientales locales y aplicación de un pesticida tópico en bovinos ${ }^{(19)}$.

En Venezuela, en 1992, hubo un brote de rabia causada por murciélagos, con 154 casos de mordeduras por vampiro, en un período de cuatro meses en la mina de oro Payapal. En este episodio, los pacientes fueron mordidos durante la noche, en su mayoría en los dedos. Es posible que los cambios introducidos por la actividad minera y el incremento de población humana favorezcan comportamientos predatorios alternativos de $D$. rotundus, recurriendo a la sangre humana como fuente de sustento ${ }^{(20)}$.

Algunos cambios epidemiológicos vienen siendo observados en América Latina. En México, el Caribe y América del Sur, hubo una reducción significativa en los casos de rabia humana debido a los programas de eliminación de rabia canina, iniciadas y coordinadas por la Organización Panamericana de la Salud (21). Por otro lado, el murciélago hematófago $D$. rotundus se está convirtiendo en el principal transmisor de esta enfermedad en dichas regiones ${ }^{(22)}$.

La región Amazónica es un área de alto riesgo. Epidemias de rabia en humanos, transmitida por $D$. rotundus han ocurrido en áreas remotas del Perú, Venezuela y Brasil, generalmente en lugares de difícil acceso (23-25). Durante los años 2004 y 2005, decenas de personas contrajeron rabia transmitida por murciélagos en esta zona, con 46 y 52 casos, respectivamente. Brasil fue el país con mayor número de casos (64), seguido por Perú (15) y Colombia
Tabla 1. Rabia humana transmitida por murciélagos hematófagos en la región amazónica, período 2004 a 2005

\begin{tabular}{lccc}
\hline País & $\mathbf{2 0 0 4}$ & $\mathbf{2 0 0 5}$ & Total \\
\hline Brasil & 22 & 42 & 64 \\
Perú & 8 & 7 & 15 \\
Colombia & 14 & 0 & 14 \\
Ecuador & 0 & 2 & 2 \\
Venezuela & 2 & 0 & 2 \\
Bolivia & 0 & 1 & 1 \\
\hline
\end{tabular}

Fuente: SVS/MS y Panaftosa/OPS

(14), considerando esos dos años ${ }^{(26)}$. La Tabla 1 muestra la ocurrencia de muertes humanas en el período mencionado, por país y año en la región amazónica.

En los lugares donde ocurrieron estos casos de rabia humana, muchas personas viven en condiciones de extrema pobreza, en casas vulnerables y áreas en la cuales la población animal es pequeña ${ }^{(27)}$. El desarrollo de una estrategia común para la prevención de rabia humana transmitida por murciélagos hematófagos en esas áreas remotas, representa un enorme desafío para América Latina (28). Debido al aislamiento extremo de algunas comunidades, las medidas preventivas deben disminuir el riesgo de exposición nocturna a los murciélagos por medio de barreras (mosquiteros) en las habitaciones locales, y tratar las mordeduras con premura. A pesar de que la vacunación pre y posexposición está indicada en estas regiones, no suele ser viable para poblaciones en localidades más apartadas ${ }^{(29)}$

Las transmisiones secundarias del virus de la rabia en seres humanos pueden ocurrir principalmente por contacto entre animales domésticos y murciélagos infectados. En el año 2001, en San Pablo, Brasil, una mujer falleció después de haber sido mordida por su gata. Después de exámenes de laboratorio e investigación epidemiológica exhaustiva, se concluyó que la mujer de 53 años de edad, adquirió el virus por la mordedura de la gata. La tipificación antigénica reveló que se trataba de la variante $3(\mathrm{AgV} 3)$, propia de murciélago hematófago D. rotundus ${ }^{(30)}$.

De manera similar, en Costa Rica, en septiembre de 2003 , hubo dos registros de fallecimiento por variante (AgV3) en una misma residencia (un niño de 9 años y una mujer de 62 años). En la investigación epidemiológica de los casos se constató una posible transmisión secundaria, pues ambas personas tuvieron antecedente de mordedura de gato que presentaba alteraciones de comportamiento ${ }^{(31)}$. En Quilichao, Colombia en el año 2008 fueron registrados dos casos de rabia en niños que fueron mordidos por un gato, la tipificación antigénica confirmó variante (AgV3) ${ }^{(32)}$. 
En el año 2006, en Minas Gerais, Brasil, un médico veterinario falleció después de manipular herbívoros infectados con el virus de la rabia. Se realizó el diagnóstico ante mortem y post mortem que confirmó que estaba involucrada la variante $\mathrm{AgV} 3{ }^{(33)}$.

En 2010 se notificó el primer caso de rabia humana por variante de murciélago hematófago en Estados Unidos. La víctima era un trabajador rural migrante, que fue mordido en el talón por un murciélago hematófago en Michoacán, México, 10 días después arribó a los Estados Unidos. Los exámenes de laboratorio confirmaron el diagnóstico de rabia, mientras que la tipificación antigénica y genética confirmó que se trataba de variante de vampiro ${ }^{(34)}$. Aunque los murciélagos hematófagos estén presentes solamente en América Latina, algunas investigaciones sugieren que la distribución geográfica de esta especie se está expandiendo debido a cambios climáticos, lo que supondría modificaciones en la dinámica y la ecología del RABV ${ }^{(35)}$.

A pesar de que los murciélagos hematófagos son observados más comúnmente en áreas rurales, hay relatos de su presencia en áreas urbanas. En Brasil, este hecho ya fue descrito en municipios de la región sudeste y nordeste ${ }^{(36,37)}$. Modificaciones en las condiciones ecológicas, consecuencia de la intensa actividad humana, como deforestación y construcciones diversas, son factores que afectan las poblaciones de murciélagos hematófagos, determinando un aumento en el número de individuos, alteración de sus hábitos y otras consecuencias ${ }^{(38)}$. Adaptaciones como mayor tolerancia a la luz, forrajeo en alturas mayores y alimentación en presas diferentes a las usuales, sugieren que $D$. rotundus se adapta al ambiente urbano ${ }^{(39)}$.

\section{IMPACTO SOCIOECONÓMICO}

Además de los problemas relacionados a salud pública, hay grandes pérdidas económicas causadas en las actividades agropecuarias. Según datos de la Organización Panamericana de la Salud (40), la rabia en animales de importancia zootécnica ocurre principalmente en América Latina. Esta especie puede alimentarse de cualquier mamífero pero tiene preferencia por la sangre de bovinos ${ }^{(41)}$.

Las actividades predatorias de quirópteros sobre el ganado acarrean pérdidas indirectas por la disminución de la productividad, la anemia, las infecciones secundarias en las heridas, la depreciación del cuero, la oclusión de canales galactóforos en fase de lactación, entre otras ${ }^{(42)}$. El anticoagulante secretado en la saliva de $D$. rotundus mantiene activa la hemorragia en la herida durante horas, causando pérdida de sangre significativa. Algunos ganaderos estimaron que la frecuencia de las lesiones infligidas por murciélagos pueden reducir el volumen de leche producido por vaca en aproximadamente $260 \mathrm{~L}$ por año y disminuir la

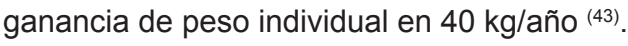

Málaga-Alba estimó en 1962 la muerte de 500 mil cabezas de ganado por año, lo que en esa época representaba 50 millones de dólares (44). Acha y Arambulo (1985) calcularon que la pérdida de más de 100 mil cabezas de ganado por año debido al RABV, equivale a 44 millones de dólares. Después del inicio de los programas de control de rabia, por medio del control de poblaciones de murciélagos hematófagos y vacunación de animales domésticos, los índices de casos de rabia en animales de abasto disminuyeron significativamente ${ }^{(45)}$. Entre los años 1993 y 2002, Belotto et al. (2005) registraron 31187 casos de rabia en América Latina, siendo que en los años de 2001 y 2002, más de la mitad de los casos sucedieron en Brasil, el país que posee el mayor efectivo bovino en la región ${ }^{(46)}$.

\section{MEDIDAS DE ESTUDIO Y CONTROL}

Estos datos deben ser vistos de manera crítica, una vez que el análisis de indicadores epidemiológicos de rabia en Brasil sugiere la ocurrencia de rabia en herbívoros de manera silenciosa, debido a fragilidad del sistema de notificación/investigación, pues la reducción del número de casos puede estar relacionada a la disminución de la vigilancia ${ }^{(47)}$. De la misma manera, aunque existan evidencias de muertes de bovinos por rabia, algunos países registran ausencia de casos en algunos años, lo que podría ser explicado por ausencia o inadecuada comunicación entre los servicios de salud y de agricultura, resultando en subnotificación ${ }^{(48)}$. Se suma a este cuadro, la poca concientización de los productores y la ineficiencia de la vigilancia epidemiológica de las instituciones oficiales responsables por el control. Se considera que por cada caso de rabia que sucede, otros diez no son notificados ${ }^{(49)}$.

El estudio de la dinámica geográfica de brotes, forma y dirección de permiten establecer un perímetro de vigilancia de $20 \mathrm{~km}$ alrededor del último caso registrado para instaurar medidas de contención, controlando la población de murciélagos hematófagos en el área afectada ${ }^{(50)}$. Inicialmente, las medidas estaban enfocadas a reducir el tamaño de las poblaciones de esta especie mediante el uso de agentes físicos o químicos, tales como gases tóxicos, fuego o humo, dinamita, armas de fuego o aplicación de venenos en las paredes de los refugios ${ }^{(51)}$. 
El conocimiento de la ecología, biología y etología de $D$. rotundus permitió el desarrollo de métodos para su control poblacional, los cuales pueden ser clasificados como de restricción y selectivos ${ }^{(51,52)}$. Estos métodos, además de impedir el acceso a las presas, controlan únicamente a esta especie, pues otras deben ser preservadas, incluso las otras dos hematófagas Diphylla ecaudata y Diaemus youngi, de las cuales hasta el momento no se comprobó que transmitan la rabia para el ganado y para el hombre. A pesar de que son especies que aún no han sido estudiadas y sus hábitos son poco conocidos, se sabe que también actúan como reservorios del RABV ${ }^{(11,15)}$.

Los métodos de restricción evitan las agresiones actuando como barreras de protección entre los animales y los murciélagos hematófagos. Un ejemplo de esto es el uso de luz como medio de protección pues $D$. rotundus es una especie lucífuga, es decir que evita áreas iluminadas ${ }^{(53)}$. Otro método de restricción son las telas de alambre, aunque estos métodos son ecológicamente correctos, no implican riesgo de salud humana y no requieren de entrenamiento para su implementación, su aplicación se restringe a rebaños pequeños por sus costos elevados ${ }^{(51)}$.

Los métodos selectivos pueden ser indirectos 0 directos y ambos se basan en la administración de anticoagulante que irá ser ingerido por los murciélagos lo cual desencadena la muerte de estos ${ }^{(53)}$.En el método indirecto, la sustancia anticoagulante es aplicada alrededor de mordeduras recientes de murciélagos hematófagos en el ganado. Este método está basado en el conocimiento del comportamiento predatorio de esta especie, por el hecho del $D$. rotundus utilizar la misma presa por más de una noche seguida para su alimentación (51,52,54). El método selectivo directo, actualmente el más utilizado en Brasil, consiste en la captura de un pequeño número de $D$. rotundus, utilizando redes de neblina y salabardas, en los corrales donde se encuentra el ganado (fuente de alimento) o directamente en sus abrigos ${ }^{(51,54)}$. Una vez capturados, se aplica tópicamente warfarina vehiculizada en vaselina sólida, en el dorso de los murciélagos y estos son liberados para que retornen al refugio, donde irán a distribuir el producto entre los demás miembros de la colonia durante los hábitos de interacción social y de higiene ${ }^{(55)}$.

Estas técnicas requieren de personal capacitado para su ejecución, pues es necesario diferenciar las especies de murciélagos y saber cómo manipularlos ${ }^{(53)}$. Deben evitarse excesos en la aplicación de la pasta vampiricida puesto que pueden presentarse muertes precoces de los murciélagos tratados, reduciendo la posibilidad de contacto con otros individuos de su colonia ${ }^{(49)}$. Ambos métodos deben comprometer únicamente a $D$. rotundus, evitando trastornos en otras especies, que desempeñan un papel importante en el mantenimiento del equilibrio ecológico ${ }^{(49)}$.

Thompson, Mitchell y Burns en 1972, desarrollaron el método de utilización de sustancia anticoagulante vía intraluminal ${ }^{(56)}$. Flores-Crespo y colaboradores desarrollaron el anticoagulante de aplicación intramuscular, a base de warfarina, estos métodos cayeron en desuso debido a la absorción irregular del anticoagulante y el corto periodo de efectividad (tres días), siendo vedado su uso en animales jóvenes, menores de un año, debido al riesgo de intoxicación ${ }^{(57,58)}$. Por otra parte, existe el anticoagulante Spot-on, en este caso se aplica la warfarina, vehiculizada en una mezcla oleosa, en el cuello, dorso y lomo de los animales, las cuales son áreas atacadas con frecuencia ${ }^{(53)}$.

Estos métodos son específicos y selectivos, eliminan solamente a $D$. rotundus y deben ser realizados por el productor, con la orientación de médicos veterinarios ${ }^{(54)}$. Los métodos de control poblacional de $D$. rotundus están comenzando a ser reevaluados, hay cuestionamientos acerca de su efectividad a largo plazo. Se cree que así como sucede con otras enfermedades infecciosas, teóricamente debe existir un umbral poblacional, esto significa estimar el número mínimo de murciélagos hematófagos que deben ser eliminados para interrumpir el ciclo de transmisión de la rabia bovina. Sin embargo, hay evidencia que sugiere que la exposición al virus en las poblaciones de $D$. rotundus no depende de la densidad poblacional de esta especie y, por el contrario, su ejecución acarrea efectos indeseados pues elimina únicamente individuos adultos con inmunidad. De esta manera los sobrevivientes son crías y juveniles sin memoria inmunológica y es a partir de estas subpoblaciones que surgirán los próximos brotes ${ }^{(59)}$.

Estudios teóricos que usan modelos matemáticos para analizar la dinámica poblacional en otras especies silvestres, sugieren que la eliminación de individuos puede paradójicamente incrementar la prevalencia y el número absoluto de individuos infectados, aumentando el riesgo de transmisión para especies domésticas ${ }^{(60)}$. Debido a la abundancia de $D$. rotundus en Brasil, sería imposible considerar erradicar la rabia bovina mediante estrategias de reducción poblacional. La estrategia de eliminación indiscriminada de murciélagos hematófagos, desorganiza la estructura demográfica de las colonias, promoviendo su dispersión a otras áreas e incrementando la posibilidad de contacto entre quirópteros $\mathrm{y}$, posiblemente, facilitando la diseminación del virus en la naturaleza ${ }^{(61)}$. Son necesarios estudios que aborden factores ecológicos y antropogénicos de la rabia para reformular las medidas de control de esta enfermedad en américa latina. 
En Brasil, el programa para el control de la rabia de herbívoros notifica los casos de rabia o mordeduras por murciélagos hematófagos en rebaños, realiza investigación epidemiológica y recolecta muestras para confirmación en laboratorio, controla la especie transmisora, vacuna los rebaños de ganado y da orientación a los productores ${ }^{(54)}$. En áreas urbanas los murciélagos sospechosos son enviados para el laboratorio para realizar confirmación de infección e identificación de la especie de quiróptero.

Los laboratorios de vigilancia epidemiológica proporcionan información que fundamenta los tratamientos profilácticos y permite modernizar las medidas de control de epizootias. Por esta razón, los métodos de diagnóstico deben ser rápidos, sensibles y específicos ${ }^{(62)}$. Las técnicas que la OMS recomienda para el diagnóstico de rabia en animales sospechosos son: inmunofluorescencia directa (IFD) e inoculación intracerebral en ratones (IVC) ${ }^{(62)}$.

La IFD es de rápida ejecución, altamente sensible y específica, detecta antígeno viral con conjugado policlonal antivirus de rabia en láminas preparadas a partir del sistema nervioso central (SNC) del animal sospechoso ${ }^{(63)}$. Para la lectura se necesita microscopio de fluorescencia. Paralelamente a la IFD se realiza la IVC debido a la posibilidad de falsos negativos por baja carga viral presente en ciertas muestras ${ }^{(63)}$

En la IVC se inocula una suspensión de la muestra sospechosa por vía intracerebral en ratones Swiss Webster recién destetados, lo cual permite el aislamiento del virus, pero se necesita confirmación posterior por IFD. El modelo animal es más sensible para el aislamiento viral pues tiene la capacidad de detectar el virus en cantidades mínimas ${ }^{(65)}$.
El diagnóstico de rabia en murciélagos no siempre es posible mediante los procedimientos convencionales, esto debido a que, en ocasiones, durante la captura, se producen daños en la arquitectura de la masa encefálica. En estos casos, el encéfalo es colectado mediante aspiración insertando una pipeta plástica a través del foramen magnum (65). Esta técnica permite preservar el cráneo para realizar la morfometría e identificar la especie, y tiene la misma eficacia en la detección de muestras positivas cuando se le compara con el método tradicional de muestreo del SNC ${ }^{(66)}$ Los restos de masa encefálica presente en la bóveda craneana pueden ser recuperados mediante lavado, el cual es un material útil para la detección de antígeno viral. (Karin Scheffer, comunicación personal).En los casos en donde no se puede usar el SNC para el diagnóstico del animal sospechoso, pueden usarse otros órganos y estructuras (glándula salivar, lengua, vejiga urinaria, corazón, pulmón, grasa interescapular, riñón, entre otros) ${ }^{(67)}$.

Además de las técnicas recomendadas por la OMS, puede ser usado el aislamiento en cultivo celular (IVCC), de ejecución más rápida y económica debido a menor tiempo de espera para la obtención de resultado en relación a la IVC ${ }^{(68)}$. Utiliza neuroblastoma murino (N2A), que presenta una sensibilidad superior en relación a las otras líneas celulares y puede ser aplicada para el aislamiento del "virus calle", su mayor susceptibilidad al virus de la rabia ${ }^{(69)}$. La sustitución de modelos animales por cultivo celular, contribuye en los aspectos éticos, especialmente en laboratorios que analizan un gran volumen de muestras de murciélago ${ }^{(70)}$.

Fuentes de financiamiento: autofinanciado.

Conflictos de interés: los autores declaran no tener conflicto de interés con los resultados del presente estudio.

\section{REFERENCIAS BIBLIOGRÁFICAS}

1. Rupprecht CE, Hanlon AC, Hemachudha T. Rabies re-examined. Lancet Infec Dis. 2002 Jun;2(6):327-43.

2. Wunner WH. Rabies. Virus. In: Jackson AC, Wunner WH, editors. Rabies, 2nd ed. Ontario, Canadá: ELSEVIER; 2007. P. 23-69.

3. Center for Disease Control and Prevention (CDC). Recovery of a patient from clinical rabies--California, 2011. MMWR Morb Mortal Wkly Rep. 2012 Feb 3;61(4):61-5.

4. Hamir AN, Niezgoda M, Rupprecht CE. Recovery from and clearance of rabies virus in a domestic ferret. J Am Assoc Lab Anim Sci. 2011 Mar;50(2):248-51.
5. Dietzschold B, Li J, Faber M, Schnell M. Concepts in the pathogenesis of rabies. Futur Virol. 2008 Sep;3(5):481-90.

6. Nadin-Davis SA. Molecular epidemiology. In: Jackson AC, Wunner WH. editors. Rabies. 2nd ed. San Diego: Elsevier; 2007. p. 69-122.

7. Favoretto SR, de Mattos C, Morais NB, Alves Araújo FA, de Mattos CA. Rabies in Marmosets (Callithrix jacchus), Ceará, Brazil. Emerg Infect Dis. 2001 NovDec;7(6):1062-5.

8. Hayman DT, Bowen RA, Cryan PM, McCracken GF, O'Shea TJ, Peel AJ, et al. Ecology of zoonotic infectious diseases in bats: current knowledge and future directions. Zoonoses and Public Health. 2013 Feb;60(1):2-21. doi: 10.1111/zph.12000.

9. Carini A. Sur une grande épizootie de rage. Annales de l'Institut Pasteur. 1911;25:843-6.

10. Haupt H, Rehaag H. Raiva epizoótica nos rebanhos de Santa Catarina, sul do Brasil, transmitida por morcegos. Bol Soc Bras Med Vet. 1925;2:17-47.

11. Torres S, Queiroz Lima E. A raiva e sua transmissão por morcegos hematófagos infectados naturalmente. Revista do Departamento Nacional de Produção Animal. 1935;2(1-3):1-53. 
12. Hurst EW, Pawan JL. An outbreak of rabies in Trinidad without history of bites, and with the symptoms of acute ascending myelitis. Lancet.1931 Set;2(5638):622-8.

13. Pawan JL. The transmission of paralytic rabies in Trinidad by the vampire bat (Desmodus rotundus murinus Wagner). Caribb Med J. 1959;21:110-36.

14. Torres $S$. A transmissão da raiva dos herbívoros pelos morcegos hematófagos da família Desmodontidae. Revista do Departamento Nacional da Produção Animal. 1934;1(2-4):165-85.

15. Silva RA, Souza AM. A ocorrência de vírus rábico em morcegos hematófagos da espécies Diaemus youngi (Jentink) no Brasil. Veterinária. 1968;1:53-5.

16. Greenhall AM, Joermann G, Schmidt U. Desmodus rotundus. Mammal Species. 1983;2002:1-6.

17. Almansa JC, Garcia RC. Incidencia del murciélago hematófago Desmodus rotundus sobre los indígenas Yanomami de Venezuela. Donana Acta Vertebr. 1980;7(1):113-7.

18. MacCarthy T. Human depredation by vampire bats (Desmodus rotundus) following a hog cholera campaign. Am J Trop Med Hyg. 1989; 40:320-2.

19. Batista-da-Costa M, Bonito RF, Nishioka SA. An outbreak of vampire bat bites in a Brazilian village. Trop Med Parasitol. 1993 Sep;44(3):219-20.

20. Caraballo AJ. Outbreak of vampire bat biting in a Venezuelan village. Rev Saude Publica. 1996 Oct;30(5):483-4.

21. World Health Organization. WHO Expert Consultation on Rabies, 2004. First report. Ginebra: WHO; 2005.

22. Schneider MC, Romijn PC, Uieda W, Tamayo H, da Silva DF, Belotto A, et al. Rabies transmitted by vampire bats to humans: An emerging zoonotic disease in Latin America?. Rev Panam Salud Publica. 2009 Mar;25(3):260-9.

23. Lopez A, Miranda P, Tejada E, Fishbein DB. Outbreak of human rabies in the Peruvian jungle. Lancet. $1992 \mathrm{Feb}$ 15;339(8790):408-11.

24. De Mattos CA, De Mattos CC, Smith JS, Miller ET, Papo S, Utrera A, Osburn BI. Genetic characterization of rabies field isolates from Venezuela. J Clin Microbiol. 1996 Jun;34(6):1553-8.

25. Castilho JG, Travassos Da Rosa ES, Mantilla A, et al. Human rabies transmitted by vampire bats: antigenic and genetic characterization of rabies virus isolates from Ecuador and Brazil. In: Anais da XVII Reunión Internacional sobre avances en la investigación y control de la rabia en las Américas; 2006 oct. 15-20; Brasilia (DF). Brasil 2006. p.73.

26. Da Rosa ES, Kotait I, Barbosa TF, Carrieri ML, Brandão PE, Pinheiro AS, et al. Bat-transmitted human rabies outbreaks, Brazilian Amazon. Emerg Infect Dis. 2006 Aug;12(8):1197-202.

27. Rupprecht CE, Barrett J, Briggs D, Cliquet F, Fooks AR, Lumlertdacha B, et al. Can rabies be eradicated? Dev Biol (Basel). 2008;131:95-121.

28. Lopez A, Miranda P, Tejada E, Fishbein DB. Outbreak of human rabies in the Peruvian jungle. Lancet. $1992 \mathrm{Feb}$ 15;339(8790):408-11.

29. Kotait I, Carrieri ML, Takaoka NY. Raiva: Aspectos gerais e clínica. Manual Técnico do Instituto Pasteur. 2009;8:1-49

30. Badilla X, Pérez-Herra V, Quirós L, Morice A, Jiménez E, Sáenz E, et al. Human rabies: a reemerging disease in Costa Rica?. Emerg Infect Dis. 2003 Jun;9(6):721-3.

31. Paez A, Polo L, Heredia D, Nuñez C, Rodriguez M, Agudelo C, et al. Brote de rabia humana transmitida por gato en el municipio de Santander de Quilichao, Colombia, 2008. Rev Salud Publica (Bogota). 2009 Dec;11(6):931-43.

32. Brito MG, Chamone TL, da Silva FJ, Wada MY, Miranda AB, Castilho JG, et al. Antemortem diagnosis of human rabies in a veterinarian infected when handling a herbivore in Minas Gerais, Brazil. Rev Inst Med Trop Sao Paulo. 2011 Jan-Feb;53(1):39-44.

33. Velasco-Villa A, Messenger SL, Orciari LA, Niezgoda M, Blanton J, Fukagawa $\mathrm{C}$ et al. Identification of new rabies virus variant in mexican immigrant. Emerg Infect Dis. 2008 Dec;14(12): 1906-8. doi: 10.3201/eid1412.080671.

34. Lee DN, Papes M, Van den Bussche RA. Present and Potential future Distribution of common Vampire Bats in the Americas and the Associated Risk to Cattle. PLOS One. 2012;7(8):e42466. doi: 10.1371/journal.pone.0042466.

35. Ferraz C, Achkar SM, Kotait I. First report of rabies in vampire bats (Desmodus rotundus) in an urban area, Ubatuba, São Paulo State, Brazil. Rev Inst Med Trop Sao Paulo. 2007 NovDec;49(6):389-90.
36. Dantas Torres F, Valença C, Andrade Filho, GV. First Record of Desmodus rotundus in urban area from the city of Olinda Pernambuco, Northeastern, Brazil: a case report. Rev Inst Med Trop Sao Paulo. 2005 Mar-Apr:47(2):107-8.

37. Taddei VA. Morcegos: algumas considerações sistemáticas e biológicas. Bol Tec CATI. 1983;72:1-31.

38. Uieda W. The common vampire bat in urban environments from Southeastern Brazil. Chiroptera Neotropical. 1995; 1(2):22-4.

39. Organización Panamericana de la Salud. Boletín Vigilancia Epidemiológica de la Rabia em las Américas. Buenos Aires: OPS; 2001.

40. Delpietro HA, Marchevsky N, Simonetti E. Relative population desities and predation of the common vampire bat (Desmodus rotundus) in natural and cattle-raising in north-east Argentina. Prev. Vet. Med. 1992 Oct;14(1-2):13-20.

41. Greenhall AM. The biting and feeding habits of the vampire bat, Desmodus rotundus. J Zool. 1972 Dec;168(4):451-61.

42. Schmidt KM, Badger DD. Some social and economic aspects in controlling vampire bats. Proc Okla Acad Sci. 1979;59:112-4.

43. Malaga Alba A. [Epidemiological factors governing the control of rabies]. Bol Oficina Sanit Panam. 1962 Aug;53:10514. [Article in Spanish]

44. Acha PN, Arambulo PV. Rabies in the tropics - history and current status. In: Kuwert E, Mérieux C, Koprowski H, Bogel $\mathrm{K}$ editors. Rabies in the tropics. Berlin: Spring-Verlag; 1985. p. 343-59.

45. Belotto A, Leanes LF, Schneider MC, Tamayo H, Correa E. Overview of rabies in the Americas. Virus Res. 2005 Jul;111(1):5-12.

46. Brasil, Ministério da Agricultura, Pecuária e Abastecimento. Análise de indicadores epidemiológicos da raiva dos herbívoros no Brasil. Brasilia: Ministério da Agricultura, Pecuária e Abastecimento; 2013.

47. Pan American Health Organization. Epidemiological surveillance of rabies in the Americas. Buenos Aires: Centro Panamericano de Zoonosis; 1993.

48. Kotait I, Gonçalves CA, Peres NF, Souza MCAM, Targueta MC. Controle da raiva dos herbívoros. Manual Técnico do Instituto Pasteur. Sao Paulo: Instituto Pasteur; 1998. 
49. Fornes A, Lord RD, Kuns ML, Largui OP, Fuenzalida E, Lazara L. Control of bovine rabies through vampire bats control. J Wildl Dis. 1974 Oct;10(4):310-6.

50. Brasil, Ministerio da Saude, Fundacao Nacional de Saude. Morcegos em áreas urbanas e rurais: manual de manejo e controle. Brasília: Fundação Nacional de Saúde/Ministério da Saúde; 1996.

51. Lord RD. Control of vampire bats. In: Greenhall AM, Schmidt U. Natural history of vampire bats. Florida: CRC Press; 1988. p. 215-26.

52. Flores-Crespo R. Técnicas, substancias y estratégicas para el control de murciélagos vampiro. Organización Panamericana de La Salud. 1 ed. México, DF: OPS; 2003.

53. Brasil, Ministério da Agricultura, Pecuária e Abastecimento. Controle da raiva dos herbívoros: manual técnico 2009. 2nd ed. Brasília: Mapa/ACS; 2009.

54. Flores-Crespo R, Arellano-Sota C. Biology and control of the vampire bat. In: Baer GM. The natural history of rabies. $2^{\text {nd }}$ ed. Flórida: CRC Press; 1991. p. 461-76.

55. Thompson RD, Mitchell GC, Burns RJ. Vampire bat controle by systemic treatment of livestock with an anticoagulant. Science. 1972 Sep $1 ; 177(4051): 806-8$.

56. Flores Crespo R, Said Fernández $S$, De Anda López D, Ibarra Velarde F, Anaya RM. A new technic for the control of vampire bats: intramuscular inoculation of cattle with warfarin. Bol Oficina Sanit Panam. 1979 Oct;87(4):283-99.

[Article in Spanish].

57. Flores-Crespo R. La rabia, los murciélagos y el control de los hematófagos.
México DF: Instituto Nacional de Investigaciones Pecuarias; 1978.

58. Streicker DG, Recuenco S, Valderrama W, Gomez Benavides J, Vargas I, Pacheco $\mathrm{V}$, et al. Ecological and anthropogenic drivers of rabies exposure in vampire bats: implications for transmission and control. Proc Biol Sci. 2012 Sep 7;279(1742):3384-92.

59. Choisy M, Rohani P. Harvesting can increase severity of wildlife disease epidemics. Proc Biol Sci. 2006 Aug 22;273(1597):2025-34.

60. Braga GB, Grisi-Filho JH, Leite BM, de Sena EF, Dias, RA. Predictive qualitative risk model of bovine rabies occurrence in Brazil. Prev Vet Med. 2014 Mar 1;113(4):536-46. doi: 10.1016/j.prevetmed.2013.12.011.

61. Kaplan MM. Safety precautions in handling rabies virus. In: Meslin F-X, Kaplan, MM, Koprowski, editors. Laboratory techniques in rabies. 4th ed. Ginebra: World Health Organization; 1996. p. 3-8.

62. Castilho JG, Nogi KI, Lima JYO, Scheffer KC, Carnieli Jr P, Oliveira RN et al. Padronização e aplicação da técnica de isolamento in vitro do vírus da raiva em células de neuroblastoma de camundongo (N2A). Boletim Epidemiológico Paulista. 2007 Nov; 4(47):12-8.

63. Koprowski, H. The mouse inoculation test. In: Meslin F-X, Kaplan MM, Koprowski $\mathrm{H}$, editors. Laboratory techniques in rabies. 4th Ed. Ginebra, World Health Organization, 1996. p. 80-7.

64. Yamamoto K, Quadros J, Queiroz LH. Use of aspiration method for collecting brain samples for rabies diagnosis in small wild animals. Zoonoses Public
Health. 2011 Feb;58(1):28-31. doi: 10.1111/j.1863-2378.2009.01282.x.

65. Gonçales JF, Carvalho C, Pedro WA, Queiroz LH. Avaliação do método de aspiração na colheita de Cérebro de morcegos para diagnóstico da raiva. Arq Inst Biol São Paulo. 2009;76(4):701-5.

66. Scheffer KC, Carrieri ML, Albas A, Santos HC, Kotait I, Ito FH. Rabies virus in naturally infected bats in the state of São Paulo, Southeastern Brazil. Rev Saude Publica. 2007 Jun;41(3):389-95. [Article in Portuguese].

67. Webster WA, Casey GA. Virus isolation in neuroblastoma cell culture. In: Meslin F-X, Kaplan MM, Koprowski H, editors. Laboratory techniques in rabies. 4th ed. Ginebra: World Health Organization; 1996. p. 96-104.

68. Rudd RJ, Trimarchi CV, Abelseth MK. Tissue culture technique for routine isolation of street bstrain rabies virus. J Clin Microbiol. 1980 Oct;12(4):590-3.

69. Silva SR, Katz IS, Mori E, Carnieli P Jr, Vieira LF, Batista HB, et al . Biotechnology advances: a perspective on the diagnosis and research of Rabies Virus. Biologicals. 2013 Jul;41(4):217-23. doi: 10.1016/j.biologicals.2013.04.002.

Correspondencia: Karin Corrêa Scheffer Ferreira

Dirección: Av. Paulista, 393. Cerquiera César. CEP 01311-000. Sao Paulo. SP. Brasil Correo electrónico: ksferreira@pasteur. saude.sp.gov.br 